\title{
Journal of Food and Health Science
}

E-ISSN 2149-0473

\section{KİNOA: BESİNSEL VE ANTİBESİNSEL ÖZELLİKLERİ}

\section{Mustafa Kürşat DEMİR, Mehmet KILINÇ}

Necmettin Erbakan Üniversitesi, Mühendislik ve Mimarlık Fakültesi, Gıda Mühendisliği Bölümü, Konya, Türkiye

Received: 06.03.2016

Accepted: 06.04.2016

Published online: 07.04.2016
Corresponding author:

Mustafa Kürşat DEMíR, Necmettin Erbakan Üniversitesi, Mühendislik ve Mimarlık Fakültesi, Gıda Mühendisliği Bölümü, , Meram, 42090, Konya, Türkiye

E-mail: mkdemir@konya.edu.tr

\section{Öz:}

Her geçen gün değişen beslenme alışkanlıklarına rağmen tahıl ve ürünleri dünya nüfusunun beslenmesinde önemli bir yer tutmaya devam etmektedir. Ancak buğday, çavdar, arpa, tritikale ve yulaf gibi tahıllar ile bunların işlenmiș ürünleri bazı insanlarda rahatsızlıklara neden olabilmektedir. $\mathrm{Bu}$ rahatsızlıklardan birisi olan Çölyak hastalığı, glutene karşı hassasiyet nedeniyle bağırsakta meydana gelen emilim bozukluğu olup, bu hastalığın en önemli özelliği; yaşam boyu sürebilen tek gıda alerjisi olmasıdır. Bu nedenle günümüzde en s1k rastlanan beslenmeye dayalı genetik hastalı olarak kabul edilmektedir. Bu problemle başa çıkmak için, genel olarak nişasta bazlı, glutensiz olarak satışa sunulan bazı gıda ürünleri piyasaya sürülmektedir ancak bu ürünler nişasta bazl olduğundan besleyici değeri düşük ürünlerdir. $\mathrm{Bu}$ nedenle glutensiz diyet ile beslenmek zorunda kalan bireyler için bu tür ürünlerin zenginleștirilmesi de önem arz etmektedir. Glutensiz bir ürün olan kinoa'ya son birkaç yılda ilgili giderek artmıştır. Kinoa; biyolojik değeri yüksek proteinleri, düşük glisemik indeksli karbonhidratları ve yine sahip oldukları fitosteroidleri, Omega-3 ve 6 yağ asitleri nedeniyle, insan sağlığ 1 açısından önemli faydalar sağlayan, tahıl benzeri (pseudocereal) bir üründür. Özellikle de, doymamış yağ asitlerini ve esansiyel aminoasitlerini yüksek miktarda içerirler. Bunların yanı sıra, mineral maddeler, vitaminler ve biyoaktif bileşenler gibi önemli mikro-besinsel bileşenlerini de yeterli ve dengeli miktarda içerirler. Ayrıca diyet lifinin de önemli bir kaynağıdır.

Anahtar Kelimeler: Kinoa, Glutensiz ürün, Beslenme

\section{Abstract: \\ Quinoa: Nutritional and Anti-Nutritional Characteristics}

Due to changing dietary habits in every passing day, cereal and cereal products have hold an important place in nutrition of the world population. However, the cereals such as wheat, rye, barley, triticale and oat and their processed products have caused some health problems in humans. Celiac disease which is one of such health problems is an intestinal malabsorption due to sensitivity against gluten and the most important feature of this disease is its being the only lifelong food allergy. For this reason, it is admitted as the most prevalent genetic disease based on nutrition. In order to overcome this problem, some gluten-free and starch based food products have been generally introduced to the market; however, these products are starch based with low nutritive value. Therefore, it is important to enrich such products for individuals who are obliged to be nourished by gluten-free diet. A special interest has been recently paid to quinoa, a gluten-free product. Quinoa is a pseudo-cereal product providing significant benefits in terms of human health since it contains high biological valued proteins, low-glycemic indexed carbohydrates and again fitosteroids, omega-3 and 6 fatty acids. When compared to other common cereal varieties, they are known to have better nutritional compositions. Especially, they contain high amounts of unsaturated essential oils and essential aminoacids. In addition, they contain adequate and balanced amounts of some micro-nutritional compounds such as mineral substances, vitamins and bioactive compounds. Furthermore, they are a significant source of dietary fibers.

Keywords: Quinoa, Gluten-free product, Nutrition 


\section{Giriş}

Her geçen gün değişen beslenme alışkanlıklarına rağmen tahıl ve ürünleri dünya nüfusunun beslenmesinde önemli bir yer tutmaya devam etmektedir. Ancak buğday, çavdar, arpa, tritikale ve yulaf gibi tahıllar ile bunların işlenmiş ürünleri, bazı insanlar üzerinde rahatsızlıklara neden olabilmektedir. Çölyak hastalığı, glutene karşı hassasiyet nedeniyle bağırsakta meydana gelen emilim bozukluğudur. Hastalığın nedenini oluşturan temel etken gluten proteininin gliadin adlı alt fraksiyonu olup, gluten içeren gıdaların tüketilmesi sonucunda başta vitamin ve mineraller olmak üzere vücudun gereksinim duyduğu çeşitli besin maddelerinin emilimi azalmaktadır (Özkaya, 1999; Battais ve ark., 2005). Gluten içeren buğday ve ürünlerinin yanı sıra, gliadinlerin homoloğu olan prolaminleri içeren, çavdar, tritikale ve arpa ürünleri de çölyak hastalarında, aynı hassasiyetin oluşmasına sebep olabilmektedir (Türksoy ve Özkaya, 2006). Gluten içeren yiyecekler tüketildiğinde, ince bağırsakta emilimi sağlayan ve parmak şekline benzeyen villusler görevini yapamaz hale gelmektedir. Çölyak hastalığının tedavisi ancak hayat boyu glutensiz bir diyete devam etmekle mümkün olabilmektedir. Bunun için de gluten proteininin diyetten tümüyle uzaklaştırılması gerekmektedir (Koning, 2003; Lee ve Newman, 2003; Butterworth ve ark., 2004). Yapilan bir çalışmada, Türkiye'deki çocuklarda çölyak hastalığının görülme sıklığ 1 1/115 olarak bulunmuştur (Ertekin ve ark., 2005). Bu oranda da anlaşılabileceği gibi, bu hastalıkta ciddi bir artış söz konusudur.

Kinoa olarak bilinen Chenopodium quinoa Willd. kazayağıgiller (Chenopodiaceae) familyasından tek yıllık bir bitki olup, son yıllarda insan ve hayvan beslenmesinde üzerinde yoğun çalışmalar yapılan glutensiz bir türdür. Kinoa yetiştiriciliği, kullanımı ve faydaları hem bilimsel araştırmalarda, hem de basın bültenlerinde sıkça yer almaya başlamıştır. Ülkemizde yeni yeni duyulmaya başlayan bu tür, ABD'de yaklaşık 10 yıldır çok yaygın olarak tüketilmektedir (Miranda ve ark., 2012). Özellikle de yüksek besinsel üstünlükleri ve biyoçeşitliliği ile gida güvenliğine ulaşma ve yoksulluğun yok edilmesine sağlayabileceği katk1sıyla tüm dünyanın dikkatini çeken kinoa, Birleşmiş Milletler (BM) tarafından da izlemeye alınmış, gelecek bin yıl kalkınma hedeflerine ulaşılmasına önemli katkı sağlama potansiyeli açısından da BM konseyi tarafından 2013 yılı Uluslararası "Kinoa Yılı" olarak ilan edilmiştir.
Bazı uzmanlara göre de, kinoa dünyadaki açlık sorununa çare olabilecek bir ürün niteliğgindedir (Tan ve Yöndem, 2013).

Kinoa (Chenopodium quinoa Willd) C3 (karbon3) bitkiler grubundan çift çenekli tek yıllık bir dane bitkisidir (Jacobsen, 2003). Kinoa, uygun olmayan iklim ve toprak koşullarına iyi adapte olabilen bir bitki olup, don (Jacobsen ve ark., 2005), kurakl1k (Geerts ve ark., 2009) ve toprak tuzluluğuna (Jacobsen, 2003) yüksek tolerans gösterebilmektedir. Anavatanı oldukça soğuk ve yüksek platolara sahip Güney Amerika'nın And bölgesi (Kolombiya, Arjantin, Peru, Bolivya, Şili ve Ekvator) olan kinoa, bu bölgede 7000 yıldan daha uzun süredir yetiştirilmektedir (Pearsall, 1992; Garcia, 2003; Bhargava ve ark., 2006; Koyun, 2013; Ruiz ve ark., 2014). Tarihsel olarak kinoa tarımı M.Ö. 5000 yılı ve daha öncesine dayandığ 1 bilinmektedir (Repo- Carrasco ve ark., 2003; Valencia- Chamorro, 2003; Repo- Carrasco- Valencia ve ark., 2011). Bu bölgede eski medeniyetlerden Aztek ve İnkaların temel besin maddesini oluşturmuş ve tahılların anası olarak isimlendirilmiştir (Tan ve Yöndem, 2013). Kinoanın kendine özgü bir aromasinın olmas1, baskın bir tat ve kokusunun olmaması gibi özelliklerinden dolayı, dünya mutfaklarında tercih edildiği gibi, Türk damak tadına uygunluğu bakımından son zamanlarda oldukça dikkat toplamıştır. Ana yemeklerden, atıştırmalık aperatif yiyeceklere kadar çok farklı şekillerde kullanım alanı mevcuttur. Kinoa tohumları un şeklinde işlenerek ekmek, makarna ve diğer tüm unlu mamullerin yapımında, buğday veya diğger tahılların unları ile karıştırılarak kullanılabilmektedir. Tane olarak pirinç gibi yemeklerde ve pilavlarda, çimlendirilen tohumları kinoa filizi olarak salata ve soğuk yemeklerde, yaprakları ise 1spanak gibi sebze olarak kullanılmaktadır. Aynı zamanda darı ile fermente edilerek, bira benzeri içeceklerin üretiminde de değerlendirilmektedir (Kaya, 2010; Koyun, 2013; Tan ve Yöndem, 2013; Demir, 2014). Ayrica kahvaltılık gevrek olarak da tüketilmektedir (Valencia-Chamorro, 2003). Besleyici özelliğinden faydalanılarak bebek mamaları yapımında da kullanılmaktadır (Koyun, 2013; Moncada ve ark., 2013).

\section{Besinsel özellikleri}

Kinoa taneleri ve ürünleri, gluten içermediği için karabuğday ve amarant gibi pseudo-cereal (tahıl benzeri) grubuna dahil edilmektedir. Glutensiz bir 
Journal abbreviation: J Food Health Sci

ürün olması nedeniyle de, gluten-free (glutensiz) diyetlerde rahatlikla kullanılabilmektedir. (Alvarez-Jubete ve ark., 2009; Pasko ve ark., 2009) Son yıllarda da yaygın olarak kullanılan tahılların sebep olduğu alerjenik risklere sahip bireyler ile vejan ve vejeteryan bireylerin diyetlerde oldukça tercih edilen yeni bir besinsel ürün haline gelmiştir (Pasko ve ark., 2009). Gerek, insan beslenmesinde önemli yeri olan protein, diyet lifi, esansiyel yă asitler, mineraller, vitaminler ve biyoaktif bileşenlerce zengin olmaları, gerekse iyi bir enerji kaynağı olmaları, kinoayı yaygın olarak kullanılan diğer tahıl çeşitlerinden farklı kılmaktadır (Valencia-Chamorro, 2003; Alvarez-Jubete ve ark., 2010). İnsan beslenmesi açısından oldukça zengin bir gida olan kinoa, FAO tarafindan yapılan karşılaştırmalarda da protein içeriğinin ve kalitesinin, yaygın olarak kullanılan tahıllara göre, çok daha yüksek olduğu ortaya konmuştur (Oelke ve ark., 1992). Tablo 1'de; kinoa tohumlarının yaygin olarak kullanılan bazı tahıllar ile karşılaştırması verilmiştir (Valencia-Chamorro, 2003).

\section{Protein ve aminoasit içeriğ $i$}

Kinoanın protein içeriği diğer tahıllardan yüksektir (Repo- Carrasco ve ark., 2003; Lindeboom, 2005; Schoenlechner ve ark., 2008), çok iyi bir protein kalitesine sahiptir ve $\%$ 8- 22 arasında protein içerebilir (Valencia- Chamorro, 2003; Jancurova ve ark., 2009). Proteinleri embriyoda yoğunlaşmış olup, bu proteinlerinin çoğunluğunu albumin ve globulin oluşturmaktadır (Repo- Carrasco ve ark., 2003; Schoenlechner ve ark., 2008). Bu proteinlerde, toplam proteinlerin \% 44- 77' sini oluşturmaktadır. Ayrıca, prolamin grubunu da (\% 0.5-7) çok az veya hiç içermezler (ValenciaChamorro, 2003; Berti ve ark., 2004; Jancurova ve ark., 2009). Kinoa, \% 37'den fazla esansiyel amino asit içerir (Koziol, 1992; Lindeboom,
2005). Tablo 2'de ise, bazı yaygın tahıllar ve süt ile kinoanın esansiyel aminoasit içerikleri kıyaslanmıştır (Koziol, 1992). Esansiyel aminoasitleri oldukça dengeli bir oranda içeren kinoa, protein kalitesi bakımından da süt proteinine yakın değerdir (Ranhotra ve ark., 1993; Repo-Carrasco ve ark., 2003). Bu besinsel üstünlük, bitki kaynaklı protein için görülmemiş bir durumdur (Ruales ve Nair, 1992). Genel olarak tahillarda düşük miktarlarda bulunan lisin aminoasidince oldukça zengindir. Önemli miktarda da metiyonin ve sistein içerir. Bu bakımdan düşük metiyonin ve sistein içeriğine sahip birçok baklagilin iyi bir tamamlayıcısıdır (Doğan ve Karwe, 2003; Jancurova ve ark., 2009; Koyun, 2013). Protein etkinlik oran1 (PER) kazeininkine benzerdir (Gross ve ark., 1989; Ranhotra ve ark., 1993). Sindirilebilirliği (\% 84.3) ise, kazeinden (\% 88.9) düşüktür. Kinoa proteinlerinin net protein kullanımı (NPU) değeri 75.2, biyolojik değeri ise 82.6 'dır (Ruales ve Nair, 1992).

\section{Karbonhidrat içeriği}

Kinoanın karbonhidrat içeriği, kuru maddede \% 67-74 arasında değişim göstermektedir (ValenciaChamorro, 2003; Jancurova ve ark., 2009). Karbonhidrat içeriğinin çoğunluğunu nişasta (\% 58.164.2) oluşturmaktadır (Lindeboom, 2005; VegaGalvez ve ark., 2010; Repo- Carrasco, 2011). Az miktarda da, monosakkarit (\% 2), ham lif (\% 2.53.9) ve pentozan (\% 2.9-3.6) bulunur (ValenciaChamorro, 2003). Amiloz içeriği (yaklaşık \% 11) ve nişasta granüllerinin çapı $(2 \mu \mathrm{m})$ diğer tahıllardan küçüktür (Repo-Carrasco ve ark., 2003; VegaGalvez ve ark., 2010). Kinoa nişastası, diğer tahıllara göre yüksek jelatinizasyon ve yüksek yapışma sıcaklığına sahiptir (Schoenlechner ve ark., 2008). Dirençli nişasta içeriği ise, buğday ve çavdardan daha düşüktür (Mikulikova ve Kraic, 2006).

Tablo 1. Kinoa tanelerin ve bazı tahıllar kimyasal kompozisyonu (g/100 g, kuru maddede)

Table 1. Chemical composition of quinoa seed and some cereals (g/100 g dry wt)

\begin{tabular}{lccccc}
\hline & Protein & Yă & Lif & Kül & Karbonhidrat \\
\hline Kinoa & 16.5 & 6.3 & 3.8 & 3.8 & 69.0 \\
Arpa & 10.8 & 1.9 & 4.4 & 2.2 & 80.7 \\
Misir & 10.2 & 4.7 & 2.3 & 11.7 & 81.1 \\
Yulaf & 11.6 & 5.2 & 10.4 & 2.9 & 69.8 \\
Pirinç & 7.6 & 2.2 & 6.4 & 3.4 & 80.4 \\
Çavdar & 13.4 & 1.8 & 2.6 & 2.1 & 80.1 \\
Buğday & 14.3 & 2.3 & 2.8 & 2.2 & 78.4 \\
& & & & \multicolumn{2}{c}{ (Valencia-Chamorro, 2003) } \\
\hline
\end{tabular}


Tablo 2. Kinoa, bazı tahıllar ve sütün esansiyel aminoasit içerikleri (g/100g protein)

Table 2. Essential amino acids of quinoa, milk and some cereals (g/100 g protein)

\begin{tabular}{lccccc}
\hline & Kinoa & Buğday & Mısır & Pirinç & Süt \\
\hline Histidin & 3.2 & 2.0 & 2.6 & 2.1 & 2.7 \\
İzolösin & 4.9 & 4.2 & 4.0 & 4.1 & 10.0 \\
Lösin & 6.6 & 6.8 & 12.5 & 8.2 & 6.5 \\
Lisin & 6.0 & 2.6 & 2.9 & 3.8 & 7.9 \\
Metiyonin & 5.3 & 3.7 & 4.0 & 3.6 & 2.5 \\
Fenilalanin & 6.9 & 8.2 & 8.6 & 10.5 & 1.4 \\
Treonin & 3.7 & 2.8 & 3.8 & 3.8 & 4.7 \\
Triptofan & 0.9 & 1.2 & 0.7 & 1.1 & 1.4 \\
Valin & 4.5 & 4.4 & 5.0 & 6.1 & 7.0 \\
& & & & & \\
\end{tabular}

\section{Lipit ve yă̆ asidi içeriği}

Kinoa, esansiyel doymamış yağ asitlerince de zengin bir içeriğe sahiptir (Ranhotra ve ark., 1993; Park ve Morita, 2004). Yağ asidi kompozisyonu, soya yağına benzemektedir (Valencia-Chamorro, 2003; Ng ve ark., 2007). Ayrica kinoa taneleri yaklaşık olarak \% 6-8 oranında toplam lipit içerirken, bu lipitlerin de büyük bir çoğunluğunu linoleik (\%52) ve linolenik asitler gibi esansiyel yağ asitleri oluşturmaktadır (Valencia-Chamorro, 2003; Park ve Morita, 2004). Tablo 3'te kinoanın doymamış yağ asitleri kompozisyonu verilmiştir. Yağ içeriğinin yüksek olması ve yine kinoa'da doğal antioksidan özellikli Vitamin-E'nin de yüksek miktarda olması (yaklaşık $700 \mathrm{ppm} \alpha$ tokoferol ve $840 \mathrm{ppm} \gamma$-tokoferol), hizlı lipid oksidasyonu önlemektedir (Koziol, 1992). Fosfolipitler toplam yağın \% 25. 2'sini oluştururlar (Przybylski ve ark., 1994). Kinoanın linoneik asit/ linonenik asit oranı yeterli miktardadır (Alvarez-Jubete ve ark., 2009; Repo- Carrasco- Valencia ve ark., 2011).

\section{Mineral madde içeriği}

Kinoanın mineral içeriği, tahıllar gibi dış kepek tabakasında toplanmıştır (Repo- Carrasco- Valencia ve ark., 2011). Mineral içeriği diğer tahılların yaklaşık iki katı kadardır. Büyüme koşulları da mineral içeriğini etkilemektedir (Karyotis ve ark., 2003). Kalsiyum, magnezyum ve demir mineralleri, glutensiz diyetler ve ürünlerinde genellikle yetersiz kalmaktadır (Thompson, 2000; Thompson ve ark., 2005). Fakat, kinoa ve diğer pseudotahıllar bu mineraller ve diğer önemli mineraller açısından zengin oldukları için besinsel açık kolaylıkla kapatılabilmektedir (Alvarez-Jubete ve ark., 2009; Alvarez-Jubete ve ark., 2010). Kinoa ve buğday örneklerinin mineral madde kompozisyonları tablo 4'de kıyaslanmıştır (Koziol, 1992). Kinoa taneleri düşük sodyum içeriğine sahip olup, kalsiyum, magnezyum, fosfor, potasyum, demir, bakır, mangan ve çinko bakımından buğday, arpa ve misırdan daha zengindir (Koziol, 1992; Valencia-Chamorro, 2003).

\section{Vitamin içeriğgi}

Kinoa, E ve B vitaminleri (özellikle de folik asit) bakımından da önemli bir besin kaynağıdır (Doğan ve Karwe, 2003; Repo-Carrasco ve ark., 2003; Alvarez-Jubete ve ark., 2010; Vega-Galvez ve ark., 2010). Kinoanın içerdiği vitaminler arasında; tiyamin $(0.4 \mathrm{mg} / 100 \mathrm{~g})$, folik asit (78.1 $\mathrm{mg} / 100 \mathrm{~g}$ ) ve C-vitamini (16.4 mg/100g) bulunmaktadır (Ruales and Nair, 1993a). Amaranth gibi riboflavin içeriği diğer tahıllardan daha fazladır (Coulter ve Lorenz, 1991; Ruales ve Nair, 1993a).

\section{Biyoaktif bileşenleri}

Kinoa taneleri oldukça yüksek miktarda biyoaktif bileşikleri (polifenoller, saponinler flavonoidler ve fenolik asitler) içermektedir. (Doğan ve Karwe, 2003; Pasko ve ark., 2009; Alvarez-Jubete ve ark., 2010). Kinoanın sahip olduğu bu biyoaktif bileşenlerin, kan kolesterol seviyelerini düşürdüğü, kanser hücrelerinin gelişimini engellediğgi, toksinleri yok ettiği, immün sistemi güçlendirdiğ $i$ ve kardiyovasküler hastalıkları önlediği bilimsel olarak ortaya konmuştur (Guzman-Maldonado ve Paredes-Lopez, 1998). 
Tablo 3. Kinoanın doymamış yağ asitleri kompozisyonu (\%)

Table 3. Unsaturated fatty acid composition (\%) of quinoa

\begin{tabular}{lccc}
\hline Kaynaklar & $\begin{array}{c}\text { Oleik } \\
(\mathbf{\%})\end{array}$ & Linoleik (\%) & $\begin{array}{c}\text { Linolenik } \\
(\mathbf{\%})\end{array}$ \\
\hline Koziol (1992) & 23.3 & 53.1 & 6.2 \\
Repo-Carrasco ve ark. (2003) & 26.0 & 50.2 & 4.8 \\
Ruales ve Nair (1993a) & 24.8 & 52.3 & 3.9 \\
\hline
\end{tabular}

Tablo 4. Kinoa ve buğday örneklerinin mineral madde kompozisyonları $(\mathrm{mg} / \mathrm{kg}$, kuru madde esasına göre)

Table 4. Mineral matter composition ( $\mathrm{mg} / \mathrm{kg}$ dry $\mathrm{wt}$ ) of quinoa and wheat samples

\begin{tabular}{ccc}
\hline Mineraller & Kinoa & Buğday \\
\hline $\mathrm{Ca}$ & 1487 & 503 \\
$\mathrm{Mg}$ & 2496 & 1694 \\
$\mathrm{~K}$ & 9267 & 5783 \\
$\mathrm{P}$ & 3837 & 4677 \\
$\mathrm{Fe}$ & 132 & 38 \\
$\mathrm{Cu}$ & 51 & 7 \\
$\mathrm{Zn}$ & 44 & 47 \\
& & (Koziol, 1992). \\
\hline
\end{tabular}

\section{Antibesinsel faktörleri}

Besinsel üstünlükleri açısından oldukça dikkat çeken kinoa'nın bazı antibesinsel özelliklere sahip olduğu da bilinmektedir. Özelliklede saponinler ve fitik asit bu anti-besinsel faktörlerin başında gelmektedir. Ayrıca tripsin inhibitörlerinde (1.36$5.04 \mathrm{TIU} / \mathrm{mg}$ ) mevcuttur. Fakat 1s1l ve islatma işlemleri sonucunda bu bileşenler inaktif olabilmektedir (Valencia-Chamorro 2003). Kinoanın (tüm tanesi) saponin içeriği \% 0.03- 2.05 arasındadır (Ridout ve ark., 1991; Chauhan ve ark., 1992; Gee ve ark., 1993; Ruales ve Nair, 1993b). Fakat bu oran soyadan daha düşüktür (Schoenlechner ve ark., 2008). Ayrıca kabuk ayırma ve yıkama işlemleri uygulanmak suretiyle $\% 72$ ' ye kadar azalt1labilmektedir (Ruales ve Nair, 1993b; Gee ve ark., 1993). Proses sirasinda da saponin miktarı azaltılabilmektedir, fakat yıkama ve kabuk ayırma işlemi kadar etkili değildir (Gee ve ark., 1993). Yakın zamana kadar saponin toksik olarak bilinmesine karşın, şimdilerde ise bazı faydalarından dolayı gıda ürünlerinde ve insan diyetinde kullanılması önerilmektedir. Örneğin; diyette saponin varlığı, safra tuz konsantrasyonu ve kolestorülün azaltmasına katkıda bulunduğu da bildirilmektedir (Valencia-Chamorro, 2003). Tahıllarda, fitik asit, genellikle embriyoda ve ruşeymde konumlanmıştır. Kinoa tohumunda ise, embriyonun yanı sıra dış tabakada da bulunmaktadır. Beş farklı kinoa varyetesi üzerinde yapılan bir çalışmada fitik asit içeriği ortalama $1.18 \mathrm{~g} / 100$ g olarak bulunmuştur (Valencia-Chamorro, 2003; Jancurova ve ark., 2009).

\section{Sonuç}

Dünya Sağl1k Örgütü (WHO)' nün verilerine göre; dünya genelinde toplam 70 milyon, ülkemizde ise yaklaşık 700 bin civarında Çölyak hastasının bulunduğu tahmin edilmektedir. Dolayısıyla bu tür genetik hastalıklar başta olmak üzere diğer yanlış ve dengesiz beslenmeye dayalı ciddi sağlık problemlerinin günden güne artacağ 1 ve acil önlemlerin alınması gerektiği başta Sağlık Bakanlığımız olmak üzere diğer kuruluşlarca da belirtilmektedir. Ayrıca son yıllarda hızlı nüfus artışı, doğal kaynakların hızla kirlenmesi, küresel ısınma ve iklim değişikliği gibi birçok faktör, bireyler üzerindeki baskıyı, özellikle de dünya nüfusunun 
artışına paralel olarak gıda ve su gereksinimi artırmıştır. Bu bakımdan; mevcut gıda kaynaklarının etkili bir şekilde kullanılması, gıda güvenliği risklerinin azaltılması ve bireylerin beslenme alışkanlıklarına bağlı olarak günlük gereksinimlerini diyetlerden dengeli bir şekilde alabilmeleri gibi etkenler, tüketicileri etkilemektedir. Bu etkenleri istenilen şekilde sağlanabilmesi için de, yeni besinlerin arayışlarına gidilmektedir. Kinoa'da bu gida hammaddelerinden birisidir. Aslında geçmişi eski medeniyetlere dayanan kinoa, Birleşmiş Milletler konseyinin gelecek bin yıl kalkınma hedeflerine ulaşılmasını adına 2013 yılını Kinoa Yılı ilan etmesiyle, tüm dünyaya yeniden tanıtılmıştır. Kinoanın en önemli özellikleri, gluten içermemesi ve oldukça yüksek besleyici değere sahip olmasıdır. Kinoa, glutensiz diyet ile hayatlarını idame etmek zorun olan ve sayıları günden güne artan Çölyak hastası bireyler için oldukça güzel bir alternatif üründür.

\section{Kaynaklar}

Alvarez-Jubete, L., Arendt, E. K. \& Gallagher, E. (2009). Nutritive value and chemical composition of pseudocereals as gluten-free ingredients. International Journal of Food Sciences and Nutrition, 60(4), 240-257.

Alvarez-Jubete, L., Arendt, E.K. \& Gallagher, E. (2010). Nutritive value of pseudocereals and their increasing use as functional gluten-free ingredients. Trends Food Science Technology, 21, 106-113.

Battais, F., Courcoux, P., Popineau, Y., Kanny, G., Moneret-Vautrin, D.A. \& Denery-Paini, S. (2005). Food allergy to wheat: differences in immunoglobulin E-binding proteins as a function of age or symptoms. Journal of $\mathrm{Ce}$ real Science, 42, 109-117.

Berti, C., Riso, P., Monti, L.D. \& Porrini, M. (2004). In vitro starch digestibility and in vivo glucose response of gluten-free foods and their gluten counterparts, European Journal of Nutrition, 43(4), 198-204.

Bhargava, A., Shukla, S. \& Ohri, D. (2006). Chenopodium quinoa-an Indian perspective. Industrial Crops and Products, 23, 73-87.

Butterworth, J.R., Banfield, L.M., Iqbal, T.H. \& Cooper, B.T. (2004). Factors relating to compliance with a gluten-free diet in patients with celiac disease: comparion of white Caucasian and South Asian patients. Clinical Nutrition, 23(5), 1127-1134.
Chauhan, G.S., Eskin, N.A.M. \& Tkachuk, R. (1992). Nutritients and antinutrients in quinoa seed. Cereal Chemistry, 69(1), 85-88.

Coulter L.A. \& Lorenz, K. (1991). Extruded corn grits-quinoa blends: I. Proximate composition, nutritional properties and sensory evaluation. Journal of Food Processing and Preservation, 15, 231-242.

Demir, M.K. (2014). Use of Quinoa Flour in The Production of Gluten-Free Tarhana. Food Science and Technology Research, 20(5), 1087-1092.

Doğan, H. \& Karwe, M.V. (2003). Physicochemical properties of quinoa extrudates. Food Science and Technology International,9(2), 101-114.

Ertekin, V., Selimoglu, M.A., Kardas, F. \& Aktas, E. (2005). Prevalence of celiac disease in Turkish children. Journal of Clinical Gastroenterology, 39(8), 689-691.

Garcia, M. (2003). Agroclimatic study and drought resistance analysis of quinoa for an irrigation strategy in the Bolivian Altiplano. Dissertationes de Agricultura Faculty of Applied Biological Sciences, K.U. Leuven, Belgium.

Gee, J.M., Price, K.R., Ridout, C.L., Wortley, G.M., Hurrell, R.F. \& Johnson, I.T. (1993). Saponins of quinoa (Chenopodium quinoa): Effects of processing on their abundance in quinoa products and their biological effects on intestinal mucosal tissue. Journal of the Science of Food and Agriculture, 63, 201209.

Geerts, S., Raes, D., Garcia, M., Taboada, C., Miranda, R., Cusicanqui, J., Mhizhac T. \& Vacher, J. (2009). Modeling the potential for closing quinoa yield gaps under varying water availability in the Bolivian Altiplano. Agricultural Water Management, 96(11), 16521658.

Gross, R., Koch, F., Malaga, I., De Miranda, A. F., Schoeneberger, H. \& Trugo, L.C. (1989). Chemical composition and protein quality of some local Andean food sources. Food Chemistry, 34 (1), 25-34.

Guzman-Maldonado S.H. \& Paredes-Lopez O. (1998). Functional products of plants indigenous to Latin America: Amaranth, quinoa, common beans and botanicals. Functional 
Journal abbreviation: J Food Health Sci

Foods: Biochemical and Processing Aspects. Lancaster: Technomic Publishing Company.

Jacobsen, S.E. (2003). The worldwide potential for Quinoa (Chenopodium quinoa Willd.). Food Reviews International, 19, 167-177.

Jacobsen, S.E., Monteros, C., Christiansen, J.L., Bravo, L.A., Corcuera, L.J. \& Mujica, A. (2005). Plant responses of quinoa (Chenopodium quinoa Willd.) to frost at various phenological stages. European Journal of Agronomy, 22, 131-139.

Jancurová, M., Minarovicová, L. \& Dandar, A. (2009). Quinoa-a review. Czech Journal of Food Sciences, 27(2), 71-79.

Karyotis, T.H., Iliadis, C., Noulas, C. \& Mitsibonas, T.H. (2003). Preliminary research on seed production and nutrient content for certain quinoa varieties in a salinesodic soil, Journal of Agronomy and Crop Science, 189(6), 402-408

Kaya, İ.Ç. (2010). Akdeniz Bölgesinde Damla Sistemiyle Tatlı ve Tuzlu Su Kullanılarak Uygulanan Farklı Sulama Stratejilerinin Quinoa Bitkisinin Verimiyle Toprakta Tuz Birikimine Etkileri ve Saltmed Modelinin Test Edilmesi. Yüksek Lisans Tezi, Çukurova Üniversitesi Fen Bilimleri Enstitüsü, Tarımsal Yapılar ve Sulama Anabilim Dalı, 122 Sayfa, Adana.

Koning, F. (2003). The molecular basis of celiac disease. Journal of Molecular Recognation, $16,333-336$.

Koyun, S. (2013). Güvenli Gida: Quinoa (Chenopodium quinoa Willd.). Mesleki Bilimler Dergisi, 2(2), 85-88.

Kozioł, M.J. (1992). Chemical composition and nutritional evaluation of quinoa (Chenopodium quinoa Willd.). Journal of Food Composition and Analysis, 5(1), 35-68.

Lee, A. \& Newman, J.M. (2003). Celiac diet: Its impact on quality of life. Journal of The American Dietetic Association, 103(11), 1533-1535.

Lindeboom, N. (2005). Studies on the characterization, biosynthesis and isolation of starch and protein from quinoa (Chenopodium quinoa willd.). Degree of Doctor of Philosophy in the Department of Applied Microbiology and Food Science University of Saskatchewan Saskatoon.
Mikulikova, D. \& Kraic, J. (2006). Natural sources of health-promoting starch. Journal of Food and Nutrition Research, 45, 69-76.

Miranda, M., Vega-Gálvez, A., Quispe-Fuentes, I., Rodríguez, M.J., Maureira, H. \& Martínez, E.A. (2012). Nutritional aspects of six quinoa (Chenopodium quinoa Willd.) ecotypes from three geographical areas of Chile. Chilean Journal of Agricultural Research,72(2), 175-181.

Moncada, G.W., González Martín, M.I., Escuredo, O., Fischer, S. \& Míguez, M. (2013). Multivariate calibration by near infrared spectroscopy for the determination of the vitamin $\mathrm{E}$ and the antioxidant properties of quinoa. Talanta, 116, 65-70.

Ng, S.C., Anderson, A., Coker, J. \& Ondrus, M. (2007). Characterization of lipid oxidation products in quinoa (Chenopodium quinoa). Food Chemistry, 101(1), 185-192.

Oelke, E.A., Putnam, D.H. \& Teynor, T.M. \& Oplinger, E.S. (1992). Alternative Field Crops Manual. http://www.hort.purdue.edu/newcrop/afcm/quinoa.html (accessed: 12 Ocak 2015).

Özkaya, B. (1999). Tahılların neden olduğu alerjiler ve önemi-2. Food Hi-Tech, Mart, 8288.

Park H. S. \& Morita, N. (2004). Changes of bound lipids and composition of fatty acids in germination of quinoa seeds. Food Science and Technology Research, 10(3), 303-306.

Paśko, P., Bartoń, H., Zagrodzki, P., Gorinstein, S., Fołta, M. \& Zachwieja, Z. (2009). Anthocyanins, total polyphenols and antioxidant activity in amaranth and quinoa seeds and sprouts during their growth. Food Chemistry, 115(3), 994-998.

Pearsall, D.M. (1992). The origins of plant cultivation in South America.. In C. W. Cowan \& P. J. Watson (Eds.) The Origins of Agriculture The Origins of Agriculture Washington, DC: Smithsonian Institute Press.

Przybylski, R., Chauhan, G.S. \& Eskin, N.A.M. (1994). Characterization of quinoa (Chenopodium quinoa) lipids. Food Chemistry, 51(2), 187-192. 
Ranhotra, G.S., Gelroth, J.A., Glaser, B.K., Lorenz, K.J. \& Johnson, D.L. (1993). Composition and protein nutritional quality of quinoa. Cereal Chemistry, 70, 303-305.

Repo-Carrasco, R., Espinoza, C., Jacobsen, S.E. (2003). Nutritional value and use of the Andean crops quinoa (Chenopodium quinoa) and kañiwa (Chenopodiumpallidicaule). Food Reviews International, 19(1-2), 179189.

Repo-Carrasco-Valencia, R.A.M. \& Serna, L.A. (2011). Quinoa (Chenopodium quinoa, Willd.) as a source of dietary fiber and other functional components. Food Science and Technology (Campinas), 31(1), 225-230.

Ridout, C.L., Price, K.R., Dupont, M.S., Parker, M.L. \& Fenwick, G.R. (1991). Quinoa saponins-analysis and preliminary investigations into the effects of reduction by processing. Journal of the Science of Food and Agriculture, 54(2), 165-176.

Ruales, J. \& Nair, B.M. (1992). Nutritional quality of the protein in quinoa (Chenopodium quinoa Willd) seeds. Plant Foods for Human $\mathrm{Nu}$ trition, 42(1), 1-11.

Ruales, J. \& Nair, B.M. (1993a). Content of fat, vitamins and minerals in quinoa (Chenopodium quinoa, Willd) seeds. Food Chemistry, 48(2), 131-136.

Ruales, J. \& Nair, B.M. (1993b). Saponins, phytic acid, tannins and protease inhibitors in quinoa (Chenopodium quinoa, Willd) seeds. Food Chemistry, 48(2), 137-143.

Ruiz, K.B., Biondi, S., Oses, R., AcuñaRodríguez, I.S., Antognoni, F., MartinezMosqueira, E.A., Coulibaly, A., Murillo, A. C., Pinto, M., Silva, A.Z., Bazile, D., Jacobsen, S.E. \& Molina-Montenegro, M.A.
(2014). Quinoa biodiversity and sustainability for food security under climate change, A review. Agronomy for Sustainable Development, 34(2), 349-359.

Schoenlechner, R., Siebendhandl, S. \& Berghofer, E. (2008). Pseudocereals, gluten-free cereal products. In E. K. Arendt \& Bello D. F. (Eds.), Food science and technology international series, (pp.161-189).

Tan, M. \& Yöndem, Z. (2013). İnsan ve hayvan beslenmesinde yeni bir bitki: Kinoa (Chenopodium quinoa Willd.). Alınteri Zirai Bilimler Dergisi, 25, 62-66.

Thompson, T. (2000). Folate, iron, and dietary fiber contents of the gluten-free diet. Journal of the American Dietetic Association, 100, 1389-1395.

Thompson, T., Dennis, M., Higgins, L.A., Lee, A.R. \& Sharrett, M.K. (2005). Gluten-free diet survey: are Americans with coeliac disease consuming recommended amounts of fibre, iron calcium and grain foods. Journal of Human Nutrition and Dietetics, 18, 163-169.

Türksoy, S. \& Özkaya B. (2006). Gluten ve Çölyak hastalığı. Türkiye 9. Gıda Kongresi, 24-26 Mayıs 2006, Bolu, sayfa: 807-810.

Valencia-Chamorro S.A. (2003). Quinoa. Encyclopedia of Food Science and Nutrition. Amsterdam: Academic Press.

Vega-Gálvez, A., Miranda, M., Vergara, J., Uribe, E., Puente, L. \& Martínez, E. A. (2010). Nutrition facts and functional potential of quinoa (Chenopodium quinoa Willd.), an ancient Andean grain: a review. Journal of the Science of Food and Agriculture, 90(15), 25412547. 